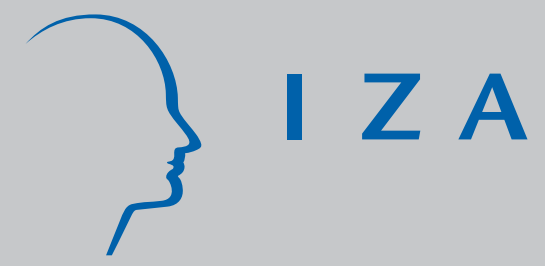

IZA DP No. 5375

Equality of Opportunity and Redistribution in Europe

Lina Dunnzlaff

Dirk Neumann

Judith Niehues

Andreas Peichl

December 2010 


\title{
Equality of Opportunity and Redistribution in Europe
}

\author{
Lina Dunnzlaff \\ University of Cologne and IZA
}

Dirk Neumann

CGS, University of Cologne and IZA

Judith Niehues

GK SOCLIFE, University of Cologne and IZA

Andreas Peichl

IZA Bonn, University of Cologne, ISER and CESifo

\section{Discussion Paper No. 5375 \\ December 2010}

\author{
IZA \\ P.O. Box 7240 \\ 53072 Bonn \\ Germany \\ Phone: +49-228-3894-0 \\ Fax: +49-228-3894-180 \\ E-mail: iza@iza.org
}

\begin{abstract}
Any opinions expressed here are those of the author(s) and not those of IZA. Research published in this series may include views on policy, but the institute itself takes no institutional policy positions.

The Institute for the Study of Labor (IZA) in Bonn is a local and virtual international research center and a place of communication between science, politics and business. IZA is an independent nonprofit organization supported by Deutsche Post Foundation. The center is associated with the University of Bonn and offers a stimulating research environment through its international network, workshops and conferences, data service, project support, research visits and doctoral program. IZA engages in (i) original and internationally competitive research in all fields of labor economics, (ii) development of policy concepts, and (iii) dissemination of research results and concepts to the interested public.
\end{abstract}

IZA Discussion Papers often represent preliminary work and are circulated to encourage discussion. Citation of such a paper should account for its provisional character. A revised version may be available directly from the author. 
IZA Discussion Paper No. 5375

December 2010

\section{ABSTRACT}

\section{Equality of Opportunity and Redistribution in Europe ${ }^{*}$}

The concept of equality of opportunity (EOp) goes back to Roemer $(1993,1998)$ who argues that a society shall guarantee its members equal access to advantage regardless of their circumstances, while holding them responsible for turning that access into actual advantage by the application of effort. Such arguments have been on the political agenda across the European Union, where the recent enlargements have brought together countries with rather different economic, social, and political backgrounds. This paper investigates how family background influences income acquisition in 15 European countries. It also scrutinizes how governments affect EOp through the design of their tax and transfer schemes. Our overall results suggest that the link between family background and economic success is usually tighter in relatively poor countries than in rich countries. Moreover, we find a clear country clustering for the Scandinavian, the Continental European, and the Anglo-Saxon countries. For Eastern Europe, our results are less definite. Looking at the impact of the tax and benefit schemes in the EU, it can be concluded that both taxes and transfers reduce inequality of opportunities, with social benefits typically playing the key role. Furthermore, the equalizing impacts of the tax benefit system on inequality of opportunity differ substantially from the ones observed when referring to the traditional notion of inequality of outcomes.

JEL Classification: D31, H24, I38

Keywords: equality of opportunity, inequality, redistribution

Corresponding author:

Andreas Peichl

IZA

P.O. Box 7240

53072 Bonn

Germany

E-Mail: peichl@iza.org

\footnotetext{
* Judith Niehues and Andreas Peichl are grateful for financial support by Deutsche Forschungsgemeinschaft DFG (GRK1461 and PE1675).
} 


\section{Introduction}

Socio-economic inequality is high on the political agenda in many European countries. In recent years, there has been a shift of the focus from inequality in incomes to inequality of opportunities (for income acquisition). The concept of equality of opportunity (EOp), proposed by Roemer $(1993,1998)$, represents a departure from the traditional notion of equality of outcome (EO), which refers to an equal distribution of economic outcomes (e.g. income, consumption or well-being) across the population. The EOp theory, in contrast, separates the influences on the outcomes an individual experiences into circumstances and effort. Circumstances are defined as all factors outside individual control, for which the society in question deems individuals should not be held accountable. These can be, for instance, social background, such as parental education, gender, age, place of birth or ethnic origin. Effort, on the other hand, comprises all actions and choices within individual responsibility for which a society holds the individual responsible, e.g. schooling choices or labor supply decisions. An EOp policy thus aims at leveling the playing field by compensating individuals for their deficits in circumstances and making it the case that, finally, only effort counts with regard to outcome achievement (Roemer $(1993,1998))$.

This paper attempts to contribute to the growing body of work in this field by analyzing inequality of opportunities for income acquisition in 15 EU member states. Furthermore, it analyzes the extent to which income taxes, social contributions and social benefits lead to a reduction of opportunity inequality in Europe. The extensive body of work on equality of opportunity has largely focused on Latin America ${ }^{1}$ and on $\mathrm{OECD}^{2}$ countries. Cross-European comparisons have only recently started to be made with the introduction of the EU-SILC micro data, the European Union Statistics on Income and Living Conditions (e.g., Checchi et al. (2008), Marrero and Rodríguez (2010b)). Our study follows this line of research by using micro data from the EU-SILC to assess the extent of EO and EOp in several European countries. We further shed light on the potential trade-off between equity and economic performance. It is widely believed that such trade-off exists for outcome equality because of its detrimental effects on incentives, while the literature is less conclusive about the relation between equality of opportunity and economic performance (e.g., Roemer (1998), Ferreira and Gignoux (2008), Barros et al. (2009), Marrero and Rodríguez (2010a)).

A second focus of this paper is on investigating how the different tax-and-transfer systems affect outcome and opportunity inequality. Since most modern theories of justice only defend compensation for inequalities due to circumstances, the empirical assessment of public policy effects on inequality of opportunity seems to be the logical second step in comprehensive EOp analysis. However, the effective impact of the tax benefit system is rarely addressed in the existing EOp literature (see, e.g., Roemer et al. (2003) and Checci et al. (2010)). Therefore, we analyze questions such as: Are redistributive policies in Europe effective in promoting equality of opportunity. If so, is this primarily a result of income taxes and social contributions or do benefit schemes play the more important role? Moreover, are improvements in terms of outcome equality associated with advances regarding opportunity equality? Answering these questions will help to identify the priorities of the different redistributive systems in the EU. In addition, if redistribution is shown to effectively level the playing field within countries, our study may provide a strong justification for redistributive measures, therewith countering the critics who claim that redistribution is unfair and ineffective.

\footnotetext{
${ }^{1}$ Bourguignon et al. (2003, 2007a), Ferreira and Gignoux (2008), and Barros et al. (2009), for example, analyze EOp in Latin America. Lately, Africa has become an additional focus of research among the less developed countries; see, for example, Cogneau and Mesplé-Somps (2008).

${ }^{2}$ Roemer et al. (2003) and Lefranc et al. (2008), for instance, examine EOp in OECD countries.
} 
Throughout our study, outcomes are defined as equivalized income. ${ }^{3}$ As circumstances variable in our EOp analysis, we consider parental background, proxied by father's and mother's level of education. It has been established by many studies ${ }^{4}$ that in Western societies, an individual's economic success is to a large part determined by his family background. Parents may influence their children's income generating capacity through various channels. These include the formation of preferences and aspirations, the genetic transmission of native abilities and also the parents' social connections in the labor market. However, since no one can choose the family into which to be born, these factors are evidently outside individual control, therewith fitting the definition of circumstances given above. Methodologically, we rank countries by applying the Gini Opportunity (GO) index developed by Lefranc et al. (2008).

Our results suggest a divide in Europe between the Continental and the Nordic countries that provide their citizens with relatively high levels of opportunity equality, and the Anglo-Saxon and Eastern European countries, where opportunities for income acquisition are relatively unequal distributed. In general, the link between family background and economic success seems tighter in poor countries than in rich countries. With regard to redistribution in the EU, we find that tax and benefit schemes partially reduce inequalities of opportunities, with social benefits being the most important factor for reducing inequality in the majority of countries. The largest income- and opportunity-equalizing effects are found in the Nordic and Continental European countries. In the Anglo-Saxon countries, in contrast, taxes and benefits only lead to relatively small improvements in income and opportunity equality. The equalizing effects of taxes and benefits on inequality of opportunity substantially differ from the ones based on inequality of outcomes.

The reminder of this paper is organized as follows: In section 2, we review the conceptual framework and introduce our methodology for measuring EOp. Section 3 presents the data set as well as the main variables of our study. Section 4 contains the results of our empirical analysis: A cross-country comparison of $\mathrm{EOp}$ and EO and an investigation of the impact of redistributive policies. Our results are further discussed in section 5 . Therein, we also analyze the relationship between economic performance and equality of opportunity. Section 6 concludes and identifies some directions for future research.

\section{Conceptual framework}

Relying on the rather philosophical work by Rawls (1971), Sen (1985), Dworkin (1981a, 1981b), Cohen (1989), and Arneson (1989), it is Roemer $(1993,1998)$ who introduces the concept of equal opportunities in the economics literature. Roemer (1998) separates the influences on the outcome an individual experiences into circumstances and effort. Circumstances are defined as including all factors outside individual control. These can be, for instance, the individual's social background, such as parental education, gender, age, place of birth or ethnic origin. Effort, on the other hand, comprises all actions and choices within individual responsibility, e.g. schooling choices and labor supply decisions or the degree to which one leads a healthy lifestyle (see Pistolesi (2009)).

Roemer (1998) argues that inequalities due to effort can be considered as equitable since they are the result of individual freedom and choice while inequalities due to differences of circumstances cannot be ethically accepted. 'Equalizing opportunities' thus means correcting unequal circumstances while leaving differences of effort unchanged. Accordingly, an 'equal opportunity society' is characterized by guaranteeing its members equal access to advantage regardless of their circumstances, but holding them responsible for turning that access into actual advantage by the application of effort (Roemer (1998), p. 24).

\footnotetext{
${ }^{3}$ We choose income as dependent or outcome variable rather than, for example, consumption, because we think that economic inequality is more about the access to, or control over economic resources than about the actual exercise of this power. See Jenkins and Van Kerm (2009) for details.

4 See Dustmann (2004), Roemer (2004), Björklund and Jäntti (2009) as well as Checchi and Peragine (forthcoming). The subsequent description of the channels through which parental background influences their offspring's income acquisition closely follows Bowles and Gintis (2002).
} 
Hence, leveling the playing field means guaranteeing that those who apply equal degrees of effort, i.e. those who are at the same rank of their respective type effort distribution, end up with equal achievements.

In accordance with Roemer (1998), we only distinguish between two generic determinants of individual outcome: circumstances $c$, which are characteristics outside individual control, and effort $\varepsilon$, representing all factors affecting earnings that are assumed to be the result of personal responsibility. We partition the population into a set of types, $T=\{1,2, \ldots, t\}$, whereby a type $t$ comprises a subset of the total population with similar circumstances.

Next, the income $y$ of individual $i$ is defined as depending both on individual circumstances and personal effort:

$$
y_{i}=f\left(c_{i}, \varepsilon_{i}\right) .
$$

An empirically suitable approximation can be obtained by log-linearization

$$
\ln y_{i t}=f(c \mid t)+\varepsilon_{i}
$$

where $y_{i t}$ denotes the income of individual $i$ of type $t$, and $f(c \mid t)$ stands for the influence of the individual's type on income. We thus assume that individual income is monotonically increasing in effort $\varepsilon_{i}$ and that $\varepsilon_{i}$ is a random term independent of circumstances $C$.

We have to deal with the informational constraint that only an individual's circumstances are observable whereas the responsibility variable, that is effort, is non-observable. While Roemer's approach measures the degree of a person's effort by her rank in the effort distribution of her type, ${ }^{5}$ we define the remaining differences in individual incomes, once the influence of circumstances has been identified, as a result of effort. Our effort variable $\varepsilon_{i}$ hence corresponds to the residual term which comprises all factors that have not been assigned to circumstances, therewith including measurement errors and transitory departures from the permanent level of income, but also luck and innate abilities. Talent and luck ${ }^{6}$ are thus not explicitly modeled, but implicitly classified as within the sphere of individual responsibility. Methodologically, effort $\varepsilon_{i}$ corresponds to the deviation between the actual value of $\ln y$ and the estimated model $\widehat{\ln y}$ :

$$
\ln y_{i t}-\widehat{\ln y_{i t}}=\varepsilon_{i} \text {. }
$$

We track the consequences of different social origins and denote opportunities as unequal as long as incomes are subject to this circumstance variable, i.e. $F(y \mid c) \neq F(y)$. Put another way, equality of opportunity is satisfied if and only if the distribution of income is independent of circumstances:

$$
\forall\left(c, c^{\prime}\right) \forall \varepsilon, \quad F(y \mid c, \varepsilon)=F\left(y \mid c^{\prime}, \varepsilon\right) .
$$

To test for the existence of EOp, we rely on the inequality of opportunity index, which was developed by Lefranc et al. (2008).

Inspired by Van de gaer (1993), Lefranc et al. (2008) develop an inequality of opportunity index, a cardinal measure that allows for a more elaborate ranking of countries in terms of EOp. Derived from the Gini index, it is called Gini opportunity (GO) index. The GO index enables us to quantify the degree of inequality of opportunity and to rank countries according to their degree of opportunity equality.

\footnotetext{
${ }^{5}$ For a summary of the procedure Roemer (1998) uses to deal with this problem and how it is applied to the ranking of income distributions, see Peragine (2004b).
}

${ }^{6}$ For a formalization that includes luck, see Ferreira and Gignoux (2008), and Lefranc et al. (2009). 
According to Lefranc et al. (2008), the GO index must fulfill five properties: First, it has to meet the requirement of within-type anonymity, i.e. the index has to be invariant to any variation of two individuals with similar circumstances. Moreover, the between-type Pigou-Dalton transfer principle must hold. Third, normalization implies that the index has to be equal to zero if the cumulative distribution functions (CDFs) corresponding to all circumstances are identical. Finally, the principle of population and scale invariance demand that the index is invariant to a replication of the population and to a multiplication of all incomes by a positive scalar.

Lefranc et al.'s (2008) proposition concentrates on the opportunity sets to which people have access and tries to make these sets as equal as possible. Hence, to comply with their approach, we first need to define a measure of the opportunities offered to the different types. In line with Lefranc et al. (2008), we measure the feasible opportunities of a given type by the area under its Generalized Lorenz (GL) curve. Next, we rank all circumstances according to twice this area, starting from the smallest one. For type $t$, whose population share is $q_{t}$, this area is equivalent to

$$
\mu_{t}\left(1-G_{t}\right)
$$

where $\mu_{t}$ is the type-specific mean income and $G_{t}$ denotes the type-specific Gini coefficient. The Gini opportunity (GO) index for income $x$ then is defined by:

$$
G O(x)=\frac{1}{\mu} \sum_{i=1}^{k} \sum_{j>i} q_{i} q_{j}\left(\mu_{j}\left(1-G_{j}\right)-\mu_{i}\left(1-G_{i}\right)\right)
$$

where the suffixes $i$ and $j$ denote different types. It computes the weighted sum of all the differences between areas of opportunity sets and thus, in essence, is a Gini aggregator of the areas under the GL curves for each type (cf. Bourguignon et al. (2007b)). As the GO index is divided by the mean income of the entire population $\mu$, it is independent of the wealth of the society. It can be shown that if the number of circumstances $t$ corresponds to the number of individuals, the GO index is equal to the Gini coefficient (cf. Lefranc et al. (2008)). Hence, it can therefore be seen as an extension of the traditional Gini index which takes values between 0 and 1 .

\section{Empirical Strategy}

In this section, we introduce the EU-SILC (European Union Statistics on Income and Living Conditions), the dataset on which our empirical analysis is based. It constitutes the largest comparative survey of European income and living conditions. After that, we depict the main variables of our analysis: Income, circumstances and effort. We thereby explain how the income and circumstance variables are generated from the EU-SILC and point out the problematic nature of the effort variable.

\subsection{The EU-SILC}

Our study relies on cross-sectional and multidimensional micro data from the EU-SILC, which is an annual survey conducted across European countries and collated by Eurostat. The EU-SILC was launched in 2004 and succeeds the European Community Household Panel (ECHP). Its comparative statistics are bound to become the new reference source for income distribution, living conditions, and social exclusion at the European level.

EU-SILC consists of two components: A household survey, which is answered by the household reference person, and an individual questionnaire for each household member aged 16 and over. At household level, the EU-SILC covers basic information on income, social exclusion, and housing. At individual level, the EU-SILC provides information on demography, education, labor force status, health and income. That way, it provides both information on individual circumstances and data on individual income, which serves as dependent variable in our analysis. 
We utilize data from the 2005 wave of the EU-SILC because its cross-sectional component is supplemented with an additional module of questions relating to intergenerational transmission of poverty. Respondents aged 25 to 65 were questioned on parental and family attributes during their teenage years (12-16 years of age). The questions cover, for instance, the occupational status of the respondents' parents and the presence of financial difficulties in the household. Most importantly, this module also provides information on parental education, which will serve as circumstance variable.

The 2005 dataset covers 24 EU member states plus Norway and Iceland. It therewith provides information on the income and living conditions of 422,400 individuals and 197,657 households. Our study, however, excludes Italy, France, Spain, Portugal, Greece, as well as Latvia and Lithuania because we have no suitable individual gross income data for these countries. Finally, Belgium, Norway, Finland and Cyprus have to be excluded, too, due to additional data limitations. Our cross-country comparison of EO and EOp thus includes 15 countries, focusing on Continental Europe (Germany, Austria, Netherlands, Luxembourg) and Scandinavia (Denmark, Sweden, Iceland) as well as on Anglo-Saxon countries (United Kingdom, Ireland). Moreover, two fifth of the countries under study is situated in Eastern Europe and encompasses the Central Eastern European (CEE) countries Poland, Czech Republic, Slovakia, Hungary and Slovenia as well as the Baltic State Estonia. The database therewith offers a high degree of heterogeneity in terms of economic features and public policy.

Since we want to confine our analysis to full-time workers, we only keep individuals who usually work 30 hours or more per week. We further restrict our sample to prime working-age individuals, aged 30 to 60 years at the time of the survey. This age interval is chosen so as to exclude students or pensioners and permit a sound and comparable analysis of earnings across types and countries. Since our small sample size only allows for the assessment of one circumstance, we exclude females and restrict our analysis to male heads of household. This sample thus consists of 34,984 males aged 44.8 years on average. Country sample sizes vary between 613 observations for Iceland and 7,793 observations for Poland.

\subsection{Income}

Income at very detailed component level is the core of the EU-SILC survey. All income variables are thereby expressed in euros and refer to the year 2004. In this study, we use equivalized individual income variables that are deduced from household data. The advantage of using variables derived from household statistics instead of personal data is that they better reflect the impact of redistributive policies, which usually aim at the entire household. Since household statistics cover all household members, benefits or allowances for unemployed or disabled individuals as well as for families, children and pensioners are all taken into account.

Our household income variables are derived starting from total household factor income and total disposable household income. The former is defined as the sum for all household members of personal factor income components plus gross income components at household level. Note that pensions are also treated as factor income. Total disposable household income corresponds to total household factor income minus taxes plus social benefits. The taxes included in this analysis comprise taxes on income and social insurance contributions, ${ }^{7}$ regular taxes on wealth and regular inter-household cash transfers paid. The social transfers considered are all in cash except for housing benefits (see Table 1). In order to analyze the effects of taxes and social benefits separately, we further include an income variable that is equivalent to total disposable household income before social transfers (compare Table 1).

\footnotetext{
7 The variable "tax on income and social insurance contributions" includes tax adjustments-repayment/receipt on income, income tax at source and social insurance contributions, if applicable, see Eurostat (2008a), p. 108.
} 
Tab. 1: Income definitions

\begin{tabular}{lll}
\hline (FI & ) EQ & Equivalized factor income \\
\hline$($ FI - TX $\quad$ ) EQ & Equivalized disposable income without social benefits \\
\hline$($ FI - TX + SB $) /$ EQ & Equivalized disposable income \\
\hline
\end{tabular}

Note: All income variables refer to annual incomes.

FI $=$ The sum of all household members gross personal income components (gross employee cash or near cash income; gross non-cash employee income (in the 2005 dataset, this variable only includes company car); gross cash-benefits or losses from self-employment (including royalties); old-age benefits; survivor'benefits) plus gross income components at household level (income from rental of a property or land; regular inter-household cash transfers received; interests, dividends, profit from capital investments in unincorporated business; income received by people aged under 16).

$\mathrm{SB}=$ Unemployment benefits; sickness benefits; disability benefits; education-related allowances; family/children related allowances; social exclusion not elsewhere specified and housing allowances.

$\mathrm{TX}=$ Taxes on income and social insurance contributions; regular taxes on wealth and regular inter-household cash transfer paid.

$\mathrm{EQ}=$ Equivalence scale.

Source: Eurostat(2008a), pp. 105-109.

We normalize household income by family size, using the household size equivalence scale. ${ }^{8}$ By dividing total household factor income and total disposable household income (adjusted with the withinhousehold non-response inflation factors) by the equivalized household size, we obtain equivalized factor income, equivalized disposable income and equivalized disposable income without social benefits. Considering individuals, rather than households, as unit of analysis makes sense since our analysis of EOp aims at identifying inequalities at the individual level.

In order to rule out any potential bias due to extreme values, we adjust all income measures by dropping the top 0.5 percent of the total income distributions and all values equal to or below zero for every country, respectively.

\subsection{Individual circumstances}

The circumstances affecting individual income are manifold. This multiplicity can partly be captured when applying a parametric estimation method as suggested by Ferreira and Gignoux (2008). The GO index, in contrast, requires a reasonable number of observations within each type, as described in section 2. Consequently we only analyze the impact of a single circumstance. In line with most of the literature on EOp (see Roemer (1998), Ferreira and Gignoux (2008), Lefranc et al. (2008) or Aaberge and Colombino (2010)), we pick the level of father's education to represent social background.

In the 2005 EU-SILC module "Intergenerational transmission of poverty", respondents were asked about the highest level of education their father had attained before and during the period the interviewee was a young teenager, i.e. between the age of 12 and 16 (Eurostat (2008b)). Respondents were asked to choose between six categories: (1) less than primary education, (2) primary education, (3) lower secondary education, (4) upper secondary education, (5) post-secondary non-tertiary education and (6) first and second stage of tertiary education. By combining education level (1), (2) and (3), as well as (4) with (5), we break

\footnotetext{
${ }^{8}$ For each person, the equivalent (per-capita) income is its household income divided by the equivalent household size according to the modified OECD scale, which assigns a weight of 1.0 to the head of household, 0.5 to every household member aged fourteen or older and 0.3 to each child aged less than fourteen. Summing up the individual weights gives the household specific equivalence factor.
} 
the data down into three categories of educational achievement. Levels (1), (2) and (3) are subsumed under 'low educational level', the combination of education levels (4) and (5) is named 'medium level of education' and level (6) constitutes the 'high educational level' (see Table 2). ${ }^{9}$

Tab. 2: The three education levels

\begin{tabular}{ll}
\hline \hline & \\
& Highest Level of Education Attained by \\
Father & Education Level \\
\hline - Second stage of tertiary education & High \\
- First stage of tertiary education & \\
\hline - Post-secondary non-tertiary education & Medium \\
- Upper secondary education & \\
\hline - Lower secondary education & Low \\
- Primary education & \\
- Less than primary education & \\
\hline \hline
\end{tabular}

\subsection{Effort}

Effort can be defined as "the human capital accumulated by the individual once he is free to make decisions for himself" (Bourguignon et al. (2003)). By implication, effort may include current effort at work, on-the-job training, but also past decisions to change jobs or region of residence. Moreover, the last part of formal schooling may also be interpreted as effort.

As described in section 2.3, the effort variable embraces all factors that are not part of circumstances. Factors such as luck, innate talent, ambition and personal preferences are thus implicitly classified as within the sphere of individual responsibility (Roemer (1998)). In this way, we follow Dworkin's (1981a, 1981b) approach of holding individuals responsible for their preferences, no matter if they were brought about by factors within or outside individual control (see section 2.1). Dissociating the influence of the family and social environment on personal preferences, as Cohen (1989) suggests, is not possible since there are no variables in the EU-SILC data set that would identify such influences.

It follows that in our study the dispersion of incomes within a type is interpreted as the result of effort only. Methodologically, effort can thus be caught by an individual's variance from his type-specific income distribution. This assumption however implicates that we are likely to overestimate the portion of inequality which is considered ethically acceptable. In our further analysis, we shall focus on identifying the influence of circumstances on income only. Effort will not be further discussed, but could be measured individually by the deviation between the actual income the individual receives and his estimated type-specific income distribution.

\footnotetext{
${ }^{9}$ As robustness check, we additionally assess the impact of parental education on EO and EOp by combining father's and mother's level of education. However, this does not qualitatively change our main findings. The results are available from the authors upon request.
} 


\section{Empirical analysis}

\subsection{The influence of family background}

We proxy family background by father's level of education. Table 3 shows the GO and corresponding Gini indices for equivalized factor income for all 15 countries under analysis. For easier comparison, all indices have been multiplied by 100. Countries are ordered from the lowest to the highest GO index, implying from most opportunity-equal to most opportunity-unequal.

The Scandinavian and Central European countries clearly head the list in terms of EOp. The Anglo-Saxon countries, in contrast, score in the bottom half of list, and are hence categorized by relatively low opportunity equality. There is a divide within the Central Eastern European (CEE) countries: The Czech and Slovak Republics, Slovenia, and Estonia score in the middle of the ranking, while Poland and Hungary mark the end of the scale. They are only surpassed by Luxembourg - the most opportunity-unequal country in this data set.

Tab. 3: GO and Gini indices for equivalized factor income

\begin{tabular}{|l|c|c|}
\hline Country & GO index & Gini index \\
\hline Denmark & 1.0 & 26.8 \\
\hline Germany & 1.5 & 30.5 \\
\hline Netherlands & 1.7 & 30.6 \\
\hline Sweden & 1.8 & 28.9 \\
\hline Iceland & 2.5 & 26.1 \\
\hline Austria & 3.2 & 30.8 \\
\hline Czech Republic & 3.9 & 29.3 \\
\hline Slovak Republic & 4.2 & 29.0 \\
\hline Estonia & 4.6 & 34.4 \\
\hline Slovenia & 4.7 & 31.9 \\
\hline United Kingdom & 4.8 & 35.2 \\
\hline Ireland & 6.4 & 35.1 \\
\hline Poland & 6.6 & 38.5 \\
\hline Hungary & 6.9 & 37.0 \\
\hline Luxembourg & 8.3 & 33.6 \\
\hline
\end{tabular}

Source: Own calculations based on EU-SILC 2005 data.

When comparing inequality of opportunity with inequality of outcomes as represented by the Gini indices in the right-hand side column, we certainly see that countries with low inequality of outcomes generally also achieve low inequalities of opportunities. Again, the group of Scandinavian countries stands out with low Gini indices. But we also see that there are some interesting changes in the ordering of countries. For example Germany and Austria score considerably better when referring to inequality of opportunity rather than outcomes. The opposite is true for the CEE countries Czech and Slovak Republic and Luxembourg. In addition, we see that the circumstance variable of father's education can only explain a rather small fraction of inequality in most countries. However, within the non-parametric framework of the GO index and our small sample size it is not possible to include further circumstance variables. Therefore our approach likely underestimates the true share of inequality of opportunity and can only 
reveal lower bounds of inequality of opportunity (Ferreira and Gignoux (2008)). Overall, although the grouping of countries remains basically the same, our results suggest important differences in the ordering of countries if we look at inequality of opportunities instead of outcomes. This is in line with Lefranc et al. (2008) and emphasizes the importance to distinguish between the different concepts of inequality assessment. As the degree of inequality is often used as a basis for the redistributive design of tax benefit systems, in the following we extend Lefranc et al. (2008) analysis and also look at the differing redistributive impact of public policies on reducing in inequality of opportunities versus inequality of outcomes.

\subsection{EOp and redistribution}

Governments can impact on the distribution of incomes and promote equality of opportunity among their citizens through the specific design of their tax and transfer policies. In the following, we examine the degree to which income taxes, social contributions and social transfers are associated with establishing more EOp, i.e. with reducing inequality of opportunity. These policies primarily aim at containing income inequality and at providing insurance against unforeseeable events. In doing so, however, they may prioritize disadvantaged groups, thus also leading to more equal opportunities. To capture the different welfare mechanisms across Europe, we analyze the impact of taxes and of social benefits separately.

For reasons of comprehensibility, we only speak of 'income taxes and social contributions' or simply 'taxes'. However, this term further subsumes regular taxes on wealth and also regular inter-household cash transfers paid (see Table 1 in section 3.2.1). ${ }^{10}$ The social benefits comprise unemployment benefits, sickness benefits, disability benefits, education-related allowances, housing and family or children related allowances as well as cash benefits and income support (Eurostat (2008a)). Note that with the exception of housing benefits, all social benefits are restricted to cash benefits. ${ }^{11}$ The effect of taxes is measured by comparing equivalized gross market income with equivalized disposable income without social benefits. When comparing the latter with equivalized disposable income including social benefits, we can capture the impact of social benefits.

\subsubsection{The effect of taxes}

To analyze how a country's tax system impacts on opportunity equality, we compare the GO indices for before- and after-tax income. Thus, Table 4 reports the GO indices without taxes on the left-hand side and after the inclusion of taxes on the right-hand side. We see that in most cases, taxes lead to a reduction in the GO index and thus in a decrease of opportunity inequality. These reductions are more pronounced in countries where opportunities are originally rather unequal, such as Ireland or Luxembourg. However, there are also countries, namely the Czech Republic, Denmark, Estonia, Germany and Slovenia in which opportunities for income generation are slightly more unequally distributed after taxation than prior to government intervention.

In Figure 1 we then contrast the relative inequality reduction by taxes in inequality of opportunity (IOp) with the reduction they achieve in inequality of outcomes $(\mathrm{IO})$. We observe substantial differences in the equalizing effects of taxes according to the two different concepts. In all countries in which taxes increase the inequality of opportunity, they achieve a reduction in inequality of outcomes. This might suggest that the design of the tax system in these countries is rather based on an EO-approach. In contrast, in countries such as Ireland, Iceland, and the Netherlands, the tax system seems to be more successful in reduc-

\footnotetext{
10 Note that only direct personal taxes are considered while indirect taxes cannot be taken into account because of lack of data. Comparing the different impact of direct and indirect taxes on EOp should be an issue of further research. Marrero and Rodríguez (2010b), for instance, find that given a country's level of development and the extent of social protection spending, countries with a tax structure primarily based on indirect taxes tend to exhibit a higher degree of EOp compared to countries that rely more heavily on financing through direct taxes.

11 The non-consideration of non-cash programs - often criticized in the literature (e.g. Brandolini and Smeeding (2009)) - is due to data limitations.
} 
ing inequality of opportunities. Therefore, according to theories of distributive justice that account for some notion of equality of opportunity, the design of these tax systems might appear "fairer" to citizens and are more likely to be accepted. This would result in lower disincentive effects of higher levels of taxation.

Tab. 4: IOp and the impact of taxes

\begin{tabular}{|l|c|c|}
\hline Country & $\begin{array}{c}\text { GO index for equiv- } \\
\text { alized factor income }\end{array}$ & $\begin{array}{c}\text { GO index for equiv- } \\
\text { alized disposable } \\
\text { income without so- } \\
\text { cial benefits }\end{array}$ \\
\hline Austria & 3.2 & 2.9 \\
\hline Czech Republic & 3.9 & 4.0 \\
\hline Denmark & 1.0 & 1.1 \\
\hline Estonia & 4.6 & 4.7 \\
\hline Germany & 1.5 & 1.7 \\
\hline Hungary & 6.9 & 6.6 \\
\hline Iceland & 2.5 & 2.3 \\
\hline Ireland & 6.4 & 5.6 \\
\hline Luxembourg & 8.3 & 7.3 \\
\hline Netherlands & 1.7 & 1.4 \\
\hline Poland & 6.6 & 6.5 \\
\hline Slovak Republic & 4.2 & 4.0 \\
\hline Slovenia & 4.7 & 4.9 \\
\hline Sweden & 1.8 & 1.7 \\
\hline United Kingdom & 4.8 & 4.6 \\
\hline
\end{tabular}

Source: Own calculations based on EU-SILC 2005 data.

However, one hypothesis could be that the equalizing capacities of taxes and social benefits are used as substitutes by the governments. Thus, in the following, we examine the impact of social benefits on EOp additionally. 
Fig. 1: Reduction in IOp and IO through taxes

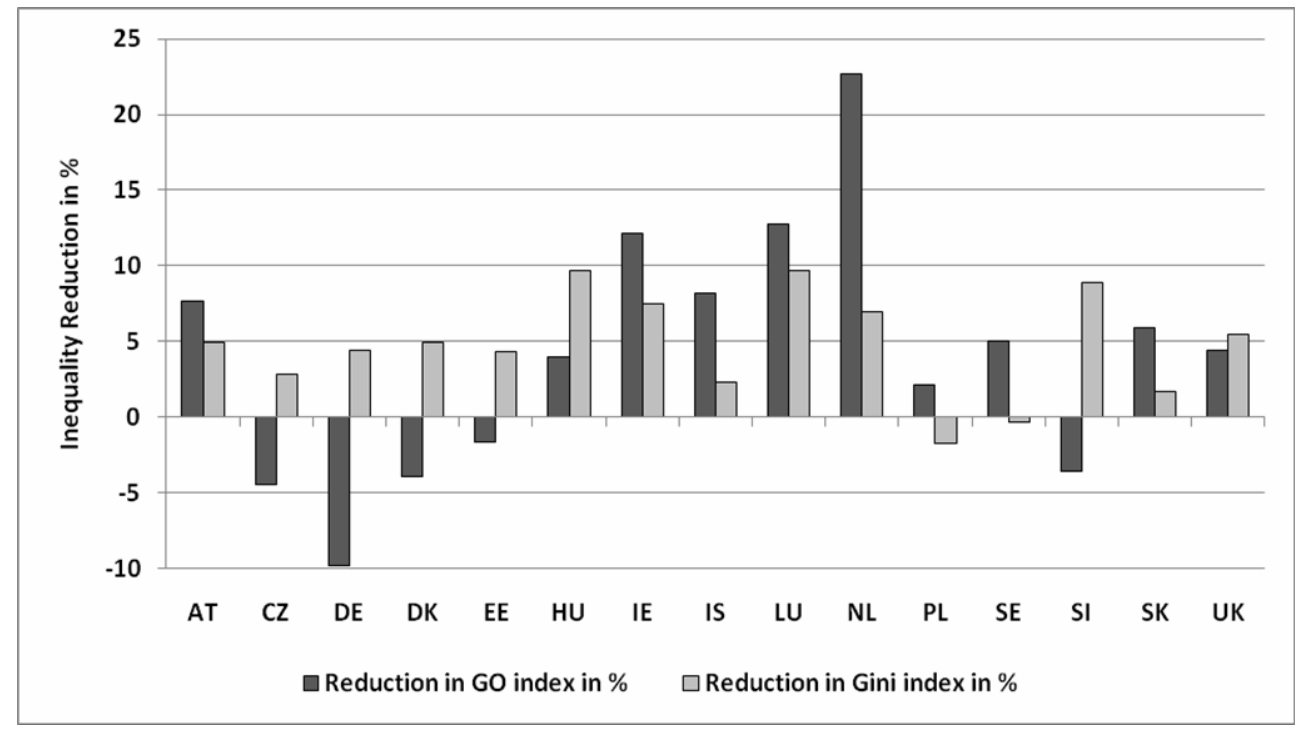

\subsubsection{The impact of social benefits}

While the effect of taxation on IOp remained partly ambiguous, the impact of social benefits is more conclusive. In Figure 2, the horizontal bars stand for the GO coefficients for equivalized disposable income with and without social benefits, respectively. It holds for all countries that the GO index for disposable income including social benefits is smaller than the coefficient for disposable income without considering social benefits. Countries are ordered according to their GO index for disposable income including social benefits, from most opportunity-equal (Denmark) to most opportunity-unequal (Luxembourg). We can see that in all 15 countries, social benefits lead to a reduction in their GO indices and therewith an increase in opportunity equality.

However, countries vary markedly in terms of the level of opportunity equality they achieve. The GO index for disposable income of Luxembourg, the least opportunity-equal country, is almost ten times larger than the Swedish one heading the list (6.6 compared to 0.7). The top performers are the Scandinavian and Continental European countries. In Sweden, for instance, social benefits lead to a reduction in the GO index of 56 percent. Next are the CEE countries Slovakia, Slovenia, and the Czech Republic. The bottom of the hierarchy is constituted by the Anglo-Saxon countries, the remaining Eastern European countries (Estonia, Hungary, and Poland), and ultimately Luxembourg. Nevertheless, this cross-country variation in opportunity inequality is still smaller than before redistribution, indicating that the direct tax and cash benefit systems narrow the overall opportunities for income acquisition across countries.

Again, in Figure 3 we compare the impact of social benefits on inequality of opportunity with their effects on the Gini index, thus on inequality of outcomes. In line with Fuest et al. (2010) we find that the equalizing effects of social benefits are substantially larger compared to those ones achieved by taxes and discussed in the previous section. However, we again observe that the impact of the social benefit system varies considerably with respect to the underlying inequality concept. For example, in the Scandinavian countries and some CEE countries such as the Slovak and Czech Republic, Slovenia and Hungary, the reduction in inequality of opportunity is higher than the reduction in the Gini index. Therefore, on the one hand, one might carefully conclude that within these countries the social benefit systems could be designed on basis of some EOp principles rather than following an EO-logic. On the other hand, in the Continental European countries and Ireland we observe the opposite. 
Fig. 2: IOp and the impact of social benefits

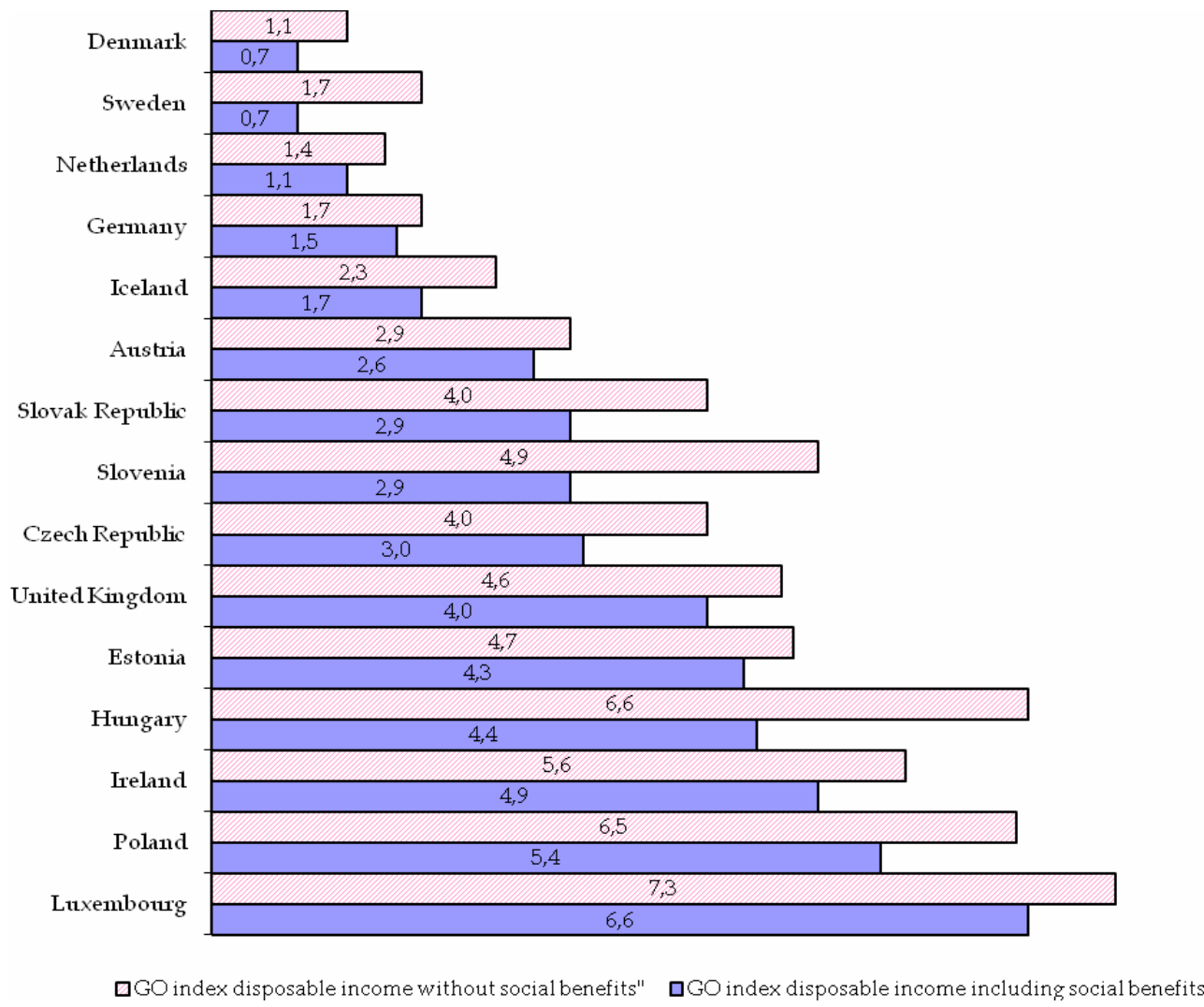

Note: For easier comparison, the GO indices have been multiplied by 100 .

Source: Own calculations based on EU-SILC 2005 data, following Brandolini and Smeeding (2008).

Fig. 3: Reduction in IOp and IO through social benefits

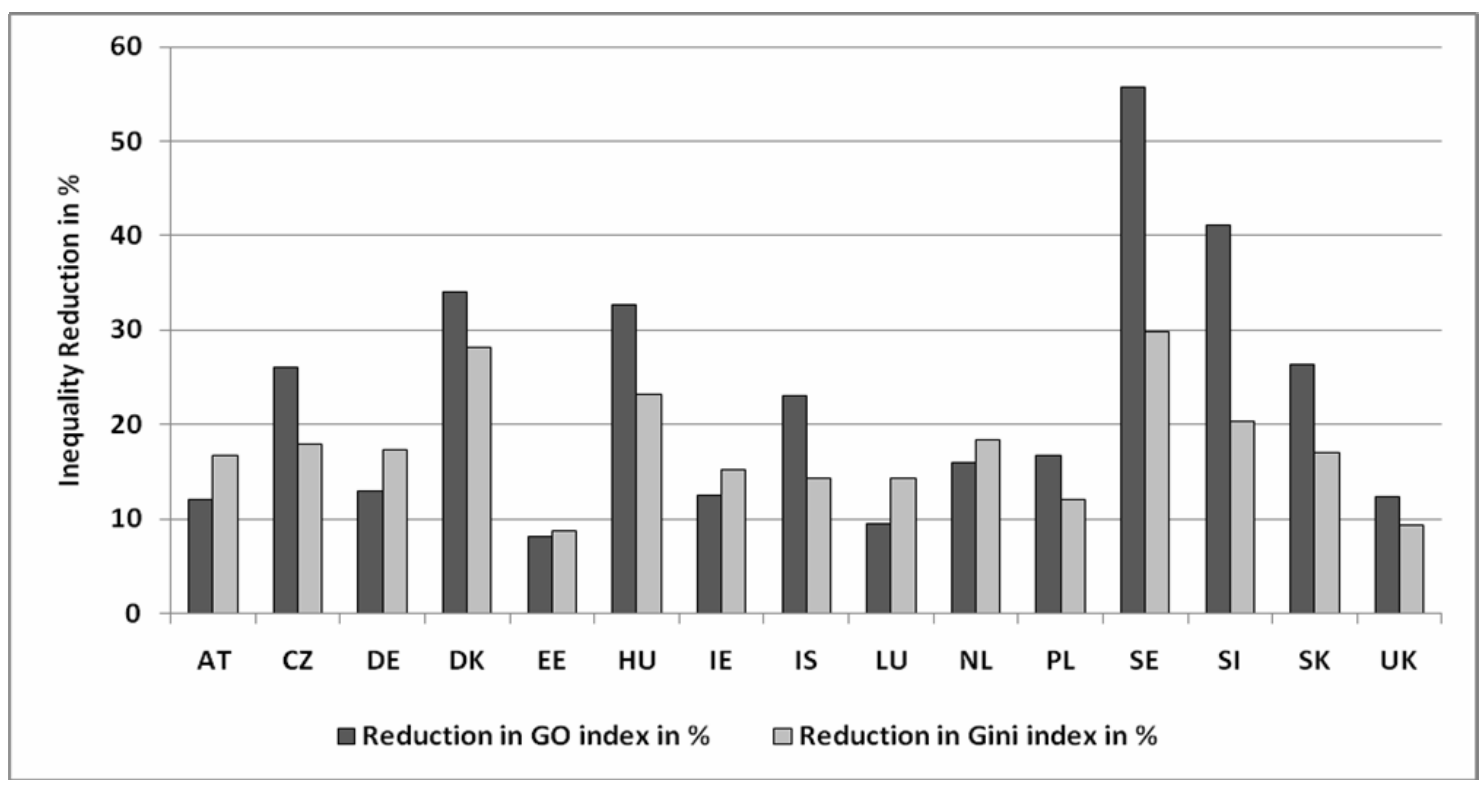




\section{Discussion of results}

From the previous section we could see that in most cases, taxes lead to a decrease of opportunity inequality while for few countries (Czech Republic, Denmark, Estonia, Germany, Slovenia) opportunities for income generation are slightly more unequally distributed after taxation than prior to government intervention. Starting from the hypothesis that the equalizing capacities of taxes and social benefits could be used as substitutes by the governments, we next examined the impact of social benefits on EOp. While the effect of taxation remained rather ambiguous, the impact of social benefits was more conclusive. All countries show a smaller GO index for disposable income including social benefits compared to the coefficient for disposable income without considering social benefits. Thus, in most of the countries, both taxes and transfers show opportunity equalizing effects and the above mentioned substitution hypothesis may only hold for a minor fraction of the sample. To assess the "equalizing logic" of the different tax and transfer systems with respect to different inequality concepts we furthermore compared the relative changes of IOp with that of IO after redistributive state intervention. Substantial differences could be observed here. In particular, in all countries in which taxes increase the inequality of opportunity, they achieve a reduction in inequality of outcomes. This might suggest that the design of the tax system in these countries is rather based on an EO-approach. When turning to the GO index including social benefits, this observation only holds for two of the five respective countries (Estonia and Germany) but now becomes true for most of the Continental European countries. Only in four countries (Iceland, Poland, Sweden, Slovakia) the whole tax benefit system seems to be designed rather on basis of EOp principles.

In a further step, we explore the potential trade-off between equity and economic efficiency. In our analysis, equity is understood as equality of opportunity measured by the GO coefficients for disposable income. Economic efficiency is gauged by a country's per capita gross domestic product (GDP). Hence, we ask for the existence of an efficiency-equity trade-off and compare the opportunity equalizing effects of the different tax and transfer systems with the economic performance of the different countries. Figure 3 reveals a strong negative correlation between our inequality measure and economic performance. All Eastern European countries are found in or at the border to the fourth quadrant, combining low GDPs per capita with high GO coefficients, i.e. with high inequality of opportunity for earnings acquisition after taxes and transfers. The Continental economies Netherlands, Germany, and Austria and the Scandinavian countries are in the opposite quadrant, performing above-average, as measured by GDP per capita while at the same time being characterized by low opportunity inequality, i.e. below-average GO coefficients. The Anglo-Saxon countries score above-average in both dimensions. This is also true for Luxembourg which, due to its high GDP per capita and fairly high GO index, constitutes an outlier in this sample.

In total, the coefficient of correlation between GDP per capita and the GO coefficient is estimated at $0.6481(p<0.01)$. This strongly negative coefficient contradicts the (theoretical) trade-off hypothesis between economic power and opportunity equality (see Roemer, 1998) - at least for our sample of countries. Quite the contrary seems to be the case: Overall, higher economic performance in the European countries under analysis is accompanied by higher levels of opportunity equality after redistributive state intervention. Thus, one might carefully conclude that an opportunity equalizing tax and transfer system and economic performance are rather mutually dependent than mutually exclusive. Yet, the direction and shape of causality is still far from being clear and further research is necessary with regard to the links between EOp and economic strength. Besides, deriving welfare statements from these findings is difficult. In a country that offers very unequal opportunities, but has a high GDP per capita, such as Ireland (see Figure 3), for instance, the welfare of the least advantaged type might be higher than if he lived in a country that exhibits both lower inequality of opportunity and lower GDP per capita like Slovakia, for example. 
Fig. 3: Equality of opportunity and GDP per capita

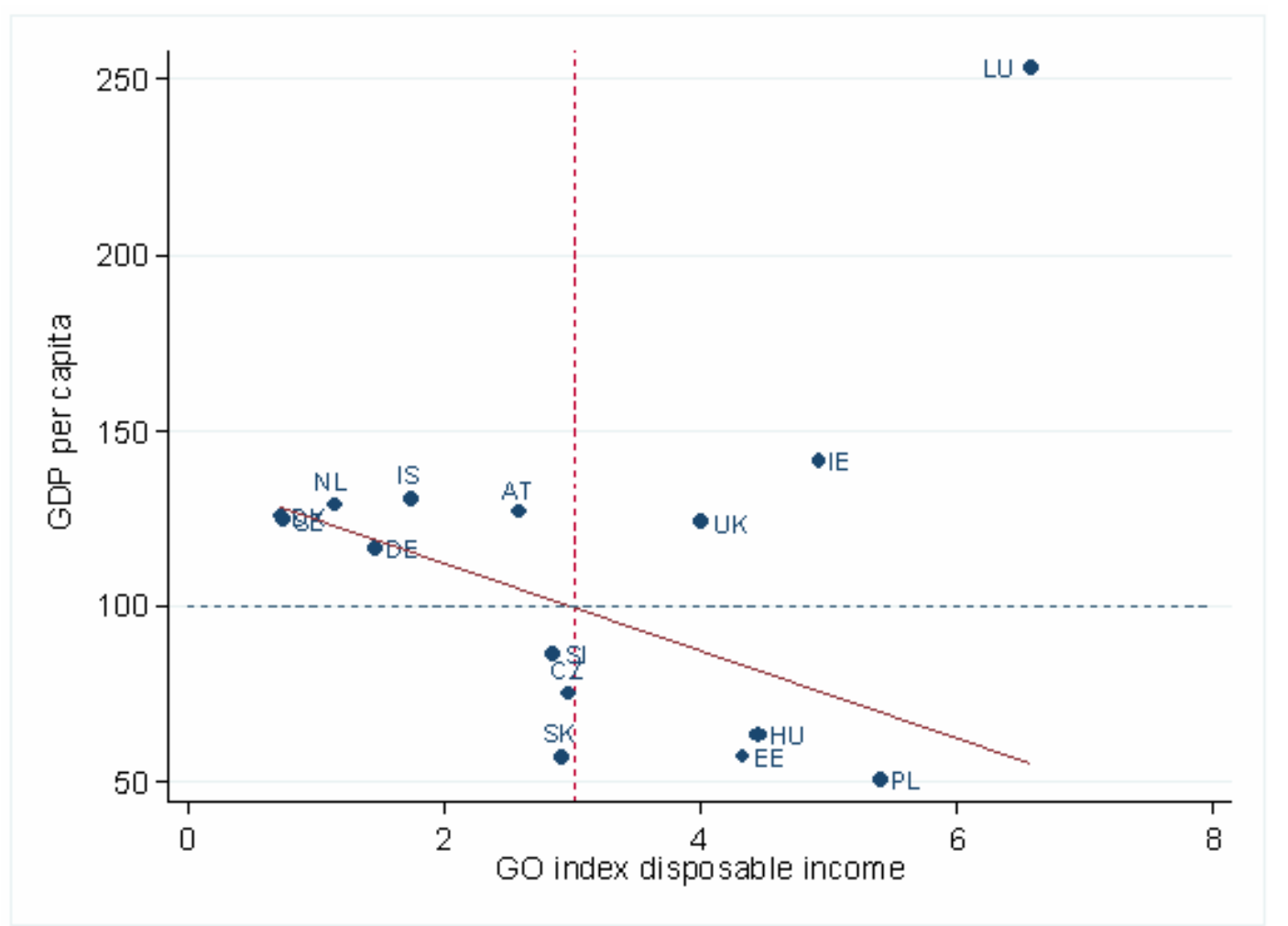

Note: For easier comparison, the GO coefficients are multiplied by 100 .

Source: Own calculations based on EU-SILC 2005.

Overall, our analysis suggests that high (low) levels of EOp are associated with above (below) average economic performance. With certain exceptions, Europe seems to be divided between the Eastern European countries, where low economic performance is accompanied by low levels of opportunity equality, and the Continental and Nordic countries that are not only economically stronger, but also provide their citizens with higher levels of EOp. Hence, the link between family background and economic success seems to be generally tighter in poor countries than in rich countries, even after redistributive state intervention. However, the Anglo-Saxon countries do not correspond to the general pattern: Being among the top economic performers, Ireland and the United Kingdom only score below-average with regard to opportunity equality. Notwithstanding these exceptions, the findings of our study contradict a general trade-off between equity and efficiency. However, more needs to be learned about the causal mechanisms linking economic performance with equality of opportunity and more research needs to be carried out with respect to the identification of opportunity equalizing public policies.

It would be most interesting to study what might explain the observed differences in opportunity equality across countries. Are they, for instance, the result of differing attitudes towards eliminating opportunity inequality among individuals in the EU member states? If preferences for EOp turn out to be country-specific, this could explain and legitimate why European welfare regimes put varying emphasis on equalizing opportunities, i.e. why redistribution is, for example, less pronounced in Estonia but plays an integral role in Finland. ${ }^{12}$

\footnotetext{
12 Kaltenthaler et al. (2008) have studied the attitudes towards eliminating income inequality in Europe, using infor-
} mation from the European Values Survey, 2000-2001. They find that the way people think about income inequality in 


\section{Conclusion}

The recent EU enlargements have brought together countries with considerably different economic backgrounds. Strengthening economic and social cohesion has therefore become a key issue in the EU, with specific attention given to equalizing opportunities between and within member states (European Commission $(2007,2008 \mathrm{a}))$. In this study, we have analyzed the status quo of opportunity equality in the EU and investigated the extent to which current tax benefit systems in Europe succeed in equalizing opportunities for their citizens. Our results suggest that differences in opportunities are still widespread both within and across EU countries. The tax and transfer schemes in the EU are generally found to reduce EOp, albeit their redistributive power differs across Europe.

Moreover, we find that Europe is divided between the Continental nations and a range of Nordic countries (Denmark, Sweden), where opportunity equality is high, and the Anglo-Saxon and Eastern European countries, where the degree of opportunity equality is relatively low. Our overall results suggest that the link between family background and economic success is usually tighter in poor countries than in rich countries. Accordingly, we cannot find a trade-off between EOp and economic performance.

Looking at the impact of the tax and benefit schemes in the EU, it can be concluded that both taxes and transfers reduce inequality of opportunities, with social benefits typically playing the key role. The largest opportunity-equalizing effects are found for Denmark and Sweden, followed by the Continental European countries. Luxembourg stands out showing the strongest link between social origin and income generation among our sample, even after redistribution. In the Anglo-Saxon countries, taxes and benefits are found to only lead to slight improvements in opportunity inequality. Furthermore, we do not find the Eastern European countries to be a uniform group when we analyze their redistributive policies. The Czech Republic, Slovakia and Slovenia perform better in terms of equalizing opportunities than their geographical neighbors who retain high absolute levels of income and opportunity inequality. Moreover, the extent of redistribution differs across Eastern Europe. Hungary's and Slovenia's income distributions experience significant improvements in terms of opportunity equality, while in Estonia, for instance, the tax and benefit systems fail to neutralize the effect of social background on economic success.

If we compare the equalizing effects of taxes and benefits across the two concepts of inequality assessment, we find substantial differences in the inequality reductions achieved by the tax benefit systems. Our results reveal that the tax systems of Germany, Denmark und the CEE countries Hungary, Slovenia and the Czech Republic are more successful at equalizing outcomes rather than opportunities. The opposite is true for the Netherlands, Luxembourg, Ireland and Iceland. Our findings also suggest that on average, the design of the social benefit system aims more at equalizing opportunities whereas the tax system is rather aimed at reducing outcome inequalities in most countries. In particular the social benefits in the Scandinavian countries and the CEE countries are designed in a way that they support equality of opportunity rather than equality of outcomes. If these tax benefit systems are perceived as fairer, they might be associated with less inefficiency compared to other systems.

Note, however, our study has several limitations. First of all, we abstract from behavioral adjustments caused by redistributive policies, thus assuming that taxes and transfers do not have any indirect influence on the pre-tax income distribution. Second, because of data restrictions, our redistributive analysis cannot take into account the effects of indirect taxes and in-kind transfers on EOp. Third, our analysis remains static since we do not consider the distribution of lifetime incomes. Future research needs to make dynamic and long-run cross-national comparisons of EOp, including various age cohorts and dif-

their society is largely a product of the ideas that they hold about politics and society and not principally a product of their economic self-interest. Moreover, they find that citizens in the cited countries Estonia and Finland exhibit rather similar attitudes towards eliminating big inequalities in income between citizens. However, our findings reveal that this is not necessarily reflected in their redistributive policies, which vary markedly (see Figure 15). Bjornskov et al. (2009) use data from the World Values Survey to investigate the relation between income inequality and happiness. It should be subject of future studies to do similar research for equality of opportunity. 
ferent periods of time. Such studies could reveal national trends and shed light on the role of economic development and globalization.

Moreover, we suggest two additional lines for further research. On the one hand, we think that more research is needed on the causal mechanisms behind the observed family associations. Behavioral economics and neuroeconomics might provide a deeper understanding of the channels through which parental background impacts their offspring's income generating capacity. Previous research on the determinants of opportunity inequality has, among other things, tried to explain unequal opportunities through native intelligence, family networking and differences in productivity (Björklund et al. (2002), Roemer et al. (2003), Checchi and Peragine (forthcoming)). Second, we suggest investigating how equality of opportunity can be best promoted. Many research findings point to the importance of education in fostering equal opportunities, such as pre-primary education, the avoidance of dropouts and ensuring instruction through at least the secondary education level (Checchi et al. (2008), Causa et al. (2009), Marrero and Rodríguez (2010b)). The stratification of the educational system, in contrast, seems to exacerbate opportunity inequalities (Brunello and Checchi (2007), Cunha and Heckmann (2007)). Others highlight the role played by labor market institutions. They find that union presence, the access to the labor market and work-support programs, such as earned income tax credits, positively impact on EOp (e.g., Checchi and Peragine (forthcoming), Checchi et al. (2010)).

The issue of equality of opportunity is central to contemporary policy design and will become even more important in view of the progressing European integration. Perhaps even Roemer's (2006) proposal to switch from per capita income as a measure of economic development to the degree, to which the society in question has equalized opportunities for income acquisition, might some day become reality. ${ }^{13}$ Research in this field therefore continues to be of utmost importance for public policy makers.

13 A measure that already comes close to this suggestion is the UNDP's Human Development Index. Moreover, Barros et al. (2009) develop a Human Opportunity Index to measure differences in opportunities among children in Latin America and the Caribbean. 


\section{References}

AABERGE, R. \& COLOMBINO, U. (2010). Accounting for family background when designing optimal income taxes: A microeconometric simulation analysis. ECINEQ Working Paper Series, 157.

ARNESON, R. (1989). Equality and equal opportunity for welfare. Philosophical Studies, 56(1), pp. 77-93.

BARROS, R. P., FERREIRA, F. H. G., MOLINAS VEGA, J. R. \& SAAVEDRA CHANDUVI, J. (2009). Measuring inequality of opportunity in Latin America and the Caribbean. The World Bank. Washington D.C..

BJÖRKLUND, A. \& JÄNTTI, M. (2009). Intergenerational income mobility and the role of family background. In Salverda, W., Nolan, B. \& Smeeding, T. M. (Eds), The Oxford handbook of economic inequality. Oxford University Press, Oxford, pp. 491-521.

BOURGUIGNON, F., FERREIRA, F. H. G. \& MENENDEZ, M. (2003). Inequality of outcomes and inequality of opportunity in Brazil. DELTA Working Papers, 24.

BOURGUIGNON, F., FERREIRA, F. H. G. \& MENENDEZ, M. (2007a). Inequality of opportunity in Brazil. Review of Income and Wealth, 53(4), pp. 585-618.

BOURGUIGNON, F., FERREIRA, F. H. G. \& WALTON, M. (2007b). Equity, efficiency and inequality traps: A research agenda. Journal of Economic Inequality, 5, pp. 235-256.

BRANDOLINI, A. \& SMEEDING, T. M. (2008). Inequality patterns in Western democracies: cross-country differences and changes over time. In Beramendi, P. \& Anderson, C. J. (Eds), Democracy, inequality, and representation. Russell Sage Foundation, New York, pp. 25-61.

BRUNELLO, G. \& CHECCHI, D. (2007). Does school tracking affect equality of opportunity? New international evidence. Economic Policy, 22(52), pp. 781-861.

CAUSA, O., DANTAN, S. \& JOHANSSON, Å. (2009). Intergenerational social mobility in European OECD countries. OECD Economics Department Working Papers, 709.

CHECCHI, D., PERAGINE, V. \& SERLENGA, L. (2010). Fair and unfair income inequalities in Europe. IZA Discussion Paper No. 5025.

CHECCHI, D., PERAGINE, V. \& SERLENGA, L. (2008). Income inequality and opportunity inequality in Europe. Rivista di Politica Economica, 9-10, pp. 263-292.

CHECCHI, D. \& PERAGINE, V. (forthcoming). Inequality of opportunity in Italy. Journal of Economic Inequality.

COGNEAU, D. \& MESPLÉ-SOMPS, S. (2008). Inequality of opportunity for income in five countries of Africa. Research on Economic Inequality, 16, pp. 99-128.

COHEN, G. A. (1989). On the currency of egalitarian justice. Ethics, 99(4), pp. 906-944.

CUNHA, F. \& HECKMAN, J. (2007). The technology of skill formation. American Economic Review, 97(2), pp. 31-47.

DUSTMANN, C. (2004). Parental background, secondary school track choice, and wages. Oxford Economic Papers, 56, pp. 209-230.

DWORKIN, R. (1981a). What is equality? Part 1: Equality of welfare. Philosophy and Public Affairs, 10, pp. $185-246$.

DWORKIN, R. (1981b). What is equality? Part 2: Equality of resources. Philosophy and Public Affairs, 10, pp. 283-345.

EUROPEAN COMMISSION (2007). Opportunities, access and solidarity: Towards a new social vision for 21st century Europe. Commission of the European Communities, Brussels. 
EUROPEAN COMMISSION (2008a). The social situation in the European Union 2007 - Social cohesion through equal opportunities. Office for Official Publications of the European Communities, Luxembourg.

EUROSTAT (2008a). Description of SILC user database variables: cross-sectional and longitudinal. Version 2006.1 from 01-03-08. Eurostat, Unit F-3, Luxembourg.

EUROSTAT (2008b). Description of SILC user database secondary target variables: Module 2005 - Intergenerational transmission of poverty. Version 2005.2 from 01-03-08. Eurostat, Unit E-2, Luxembourg. Retrieved May 23, 2010, from http://circa.europa.eu/Public/irc/dsis/eusilc/library?l=/data_dissemination/udb_user_database/module_descript iondoc/_EN_1.0_\&a=d.

FERREIRA, F. H. G. \& GIGNOUX, J. (2008). The measurement of inequality of opportunity: Theory and an application to Latin America. The World Bank Policy Research Working Papers, 4659.

FUEST, C., NIEHUES, J. \& PEICHL, A. (2010). The redistributive effects of tax benefit systems in the enlarged EU. Public Finance Review, 38, pp. 473-500.

JENKINS, S. P. \& VAN KERM, P. (2009). The measurement of economic inequality. In Salverda, W., Nolan, B. \& Smeeding, T. M. (Eds), Economic Inequality. Oxford University Press, Oxford, pp. 40-67.

KALTENTHALER, K., CECCOLI, S. \& GELLENY, R. (2008). Attitudes towards eliminating income inequality in Europe. European Union Politics, 9, pp. 217-241.

LEFRANC, A., PISTOLESI, N. \& TRANNOY, A. (2008). Inequality of opportunities vs. inequality of outcomes: Are Western societies all alike? Review of Income and Wealth, 54(4), pp. 513-543.

LEFRANC, A., PISTOLESI, N. \& TRANNOY, A. (2009). Equality of opportunity and luck: Definitions and testable conditions, with an application to income in France. Journal of Public Economics, 93, pp. 1189-1207.

MARRERO, G. A. \& RODRÍGUEZ, J. G. (2010a). Inequality of opportunity and growth. ECINEQ Working Paper Series, 154.

MARRERO, G. A. \& RODRÍGUEZ, J. G. (2010b). Inequality of opportunity in Europe: Economic and policy facts. ECINEQ Working Paper Series, 172.

PERAGINE, V. (2004b). Ranking income distributions according to equality of opportunity. Journal of Economic Inequality, 00, pp. 1-20.

PERAGINE, V. \& SERLENGA, L. (2008). Higher education and equality of opportunity in Italy. Research in Economic Inequality, 16, pp. 67-98.

PISTOLESI, N. (2009). Inequality of opportunity in the land of opportunities, 1968-2001. Journal of Economic Inequality, 7, pp. 411-433.

RAWLS, J. (1971). Theory of justice. Harvard University Press, Cambridge, Massachusetts.

ROEMER, J. E. (1993). A pragmatic theory of responsibility for the egalitarian planer. Philosophy and Public Affairs, 22, pp. 146-166.

ROEMER, J. E. (1996). Theories of Distributive Justice. Harvard University Press, Cambridge, Massachusetts.

ROEMER, J. E. (1998). Equality of opportunity. Harvard University Press. Cambridge, Massachusetts.

ROEMER, J. E., AABERGE, R., COLOMBIO, U., FRITZELL, J., JENKINS, S., LEFRANC, A., MARX, I., PAGE, M., POMMR, E., RUIZ-CASTILLO, J. SAN SEGUNDO, M. J., TRANAES, T., TRANNOY, A., WAGNER, G. \& ZUBIRI, I. (2003). To what extent do fiscal regimes equalize opportunities for income acquisition among citizens? Journal of Public Economics, 87, pp. 539-565.

SEN, A. K. (1985). Commodities and capabilities. Elsevier Science Publishers, Amsterdam.

VAN DE GAER, D. (1993). Equality of opportunity and investment in human capital. Ph.D. paper, Katholieke Universiteit Leuven. 